\title{
INTELLIGENT DESIGN AND OPTIMIZATION OF MACHINING FIXTURES
}

\author{
Djordje Vukelic, Goran Simunovic, Branko Tadic, Borut Buchmeister, Tomislav Saric, Nenad Simeunovic
}

Original scientific paper

This work presents an integral system for machining fixture layout design and optimization. The optimization module of this system allows determination of optimal positions of locating and clamping elements, which provides required accuracy and surface quality, while at the same time guarantees design of collision-free fixtures. The design module performs selection of required fixture elements based on a set of predefined production rules. Adequate criteria for the selection of fixture elements are defined for locating, clamping, tool guiding, and tool adjustment elements, as well as for fixture body elements, connecting elements and add-on elements. The system uses geometry and feature workpiece characteristics, as well as the additional machining, and process planning information. It has been developed to accommodate machining processes of turning, drilling, milling, and grinding of rotational and prismatic workpieces. A segment of output results is also shown. Finally, conclusions are presented with directions for future investigation.

Keywords: artificial intelligence; fixture; process planning

Inteligentno projektiranje i optimizacija konstrukcija naprava za strojnu obradu

Izvorni znanstveni rad

U radu je predstavljen integralni sustav za projektiranje i optimizaciju konstrukcije naprava za strojnu obradu. Dio sustava za optimizaciju omogućuje, s jedne strane, određivanje optimalnih pozicija elemenata za baziranje i stezanje kako bi se postigla potrebna točnost i kvaliteta obrađene površine izratka, a s druge strane, generiranje konstrukcije naprava bez kolizija. Dio sustava za projektiranje osigurava izbor pojedinih elemenata naprava na osnovi prethodno definiranih produkcijskih pravila. Prilagođeni kriteriji izbora definirani su za elemente za baziranje, elemente za stezanje, elemente za vođenje alata, elemente za podešavanje položaja alata, elemente tijela naprava, elemente za povezivanje i nadogradne elemente. Sustav je baziran na geometrijskim karakteristikama i karakterističnim obilježjima djela, kao i dodatnim informacijama o obradi i informacijama iz tehnološkog procesa. Sustav je razvijan za operacije tokarenja, bušenja, glodanja i brušenja koje se izvode na rotacijskim i prizmatičnim radnim predmetima. U radu su djelomično prikazani izlazni rezultati razvijenog sustava. Na kraju rada dani su odgovarajući zaključci i istaknuti mogući pravci daljih istraživanja.

Ključne riječi: naprava; tehnološki proces; umjetna inteligencija

\section{Introduction}

Within a manufacturing system, there are several factors which most prominently influence the quality of process plans: blanks, structure of machining processes, concentration of machining operations, machine tools, cutting tools, fixtures, measuring devices, etc. Fixtures are devices which are used for rapid and reliable locating, supporting and clamping of workpiece, in a way which enable machining within tolerances [1]. Fixtures have direct influence on the machining quality, productivity and product cost. The costs associated with the design and manufacture of fixtures is sizeable, accounting for some $10-20 \%$ of the total cost of a manufacturing system [2]. These costs do not pertain solely to fixture material, manufacture, and assembly, but also include the costs of fixture design [3]. By lowering the fixture design costs one can achieve significant economic effects. This can be done by applying new methods in fixture design [4]. Simplification of the design process is primarily centred on design automation, i.e., the development of CAFD (Computer Aided Fixture Design) systems. Present research in the domain of computer aided fixture design

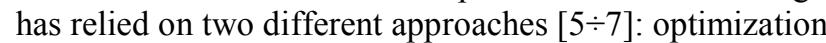
of fixture design and development of fixture design systems.

Various techniques have been used for optimization of fixture design: finite element analysis (FEA), genetic algorithms (GA), artificial neural networks (ANN), as well as the combinations of some methods such as FEA and GA, GA and ant colony algorithm (ACA), ACA and FEA, etc. Krishnakumar and Melkote [8] presented a GAbased discrete fixture layout optimization method to minimize the deformation of the workpiece under static conditions. Hamedi [9] presented a fixture design system which integrated nonlinear FEA into the ANN and GA. The GA-based program is used to search for the optimal value of clamping forces with small deformation/stress in the component. Sanchez et al. [10] calculated the contact load at the fixture-workpiece interface using a simple and direct mathematical tool along with the FEA, which simplified the deformation minimisation problem. Prabhaharan et al. [11] presented a fixture layout optimization method that used GA and ACA separately. Workpiece deformation was modeled using FEA for the problems of fixture layout optimization with the objective of minimizing the dimensional and form errors. Asante [12] presented a model that combines contact elasticity with FEA to predict contact loads and pressure distribution at the contact region in a workpiece-fixture system. Chen et al. [13] presented a fixture layout design and clamping force optimization procedure based on the GA and FEA. The optimization procedure was multiobjective: minimizing the maximum deformation of the machined surfaces and maximizing the uniformity of deformation. Vishnupriyan et al. [14] optimized the fixture layout in order to minimize the machining error considering both a geometric error of locating elements and elastic deformation of a workpiece. Both of these parameters were simultaneously optimised using a GA. Tadic et al. [15] proposed an approach to workpiece clamping based on intentional plastic deformation of workpiece in some predefined narrow zones. They analyzed load capacity and compliance of these interfaces. Vishnupriyan et al. [16] proposed a method of using an ANN for the prediction of a dynamic workpiece motion. They optimized parameters of the ANN using a GA to achieve better prediction capability of the ANN 
and minimize different forms of errors in training and generalization. Liu et al. [17] presented a geometric model considering both the workpiece surface and the locator shape. A FEA-based force-deformation model was developed to compute the node displacements under external forces. Bai et al. [18] described an approach based on memetic algorithm to multi-objective fixture layout optimization, considering both location accuracy and stability. This approach used an entropy method to obtain the weights of each objective functions, and establishes a fitness function. A memetic algorithm was developed to properly select the positions of locators to minimize the fitness function. Wang et al. [19] proposed a fixture optimization methodology for turbine blade. Geometric locating tolerance analysis and FEA based structural deformation prediction methods were integrated into one framework to improve the machining performance of a thin-walled turbine blade. Tadic et al. [20] focused on the problem of compliance of interface between clamping/locating fixture elements and workpiece. The results of experimental investigation showed that the clamping/locating elements with largerradius spherical tips provide significantly lower interface compliance.

Those types of research are more or less focused on defining optimal location for certain fixture elements, most often the locating and/or clamping elements. In this way, it is possible to define all the suitable locations for particular fixture elements. However, the main drawback of this approach is that it fails to provide selection of particular fixture elements, as well as the final fixture solution. Instead, the user is presented with conceptual design. The road from conceptual to detailed design is not only long, but there is a question whether the problem can be solved at all.

When discussing the development of fixture design systems, there are several approaches worth noting: artificial neural networks (ANN), systems based on casebased reasoning (CBR) methodology, expert systems, and other knowledge-based systems. Dai et al. [21] described a method for application of a rule-based reasoning on the modular element database, which can be used effectively for integrating with a CAD system and for modelling fixture subassemblies. Lin and Huang [22] presented modular fixture planning system which combines the pattern recognition capability of the ANN and the concept of group technology to group the workpieces with different patterns but identical fixture modes into the same group. Ma and Rong [23] presented an automated fixture design system, in which the fixturing surfaces are automatically determined based on geometric and operational information. Kumar et al. [24] developed a classification model and classification rules for conceptual design of fixture in milling and drilling process, for prismatic parts. Gologlu [25] presented a rule-based reasoning methodology for setup planning and datum selection incorporating machining and fixturing constraints. Liqing and Kumar [26] developed internetenabled CBR system for fixture design and implemented in client-server mode architecture. Case representation is described using XML (eXtensible Markup Language) format. $\mathrm{Hu}$ et al. [27] proposed a method of selecting a type for checking fixtures that harnesses advantages of
ANN. This method attempts to capture relevant domain knowledge and is used to produce acceptable solutions. Boyle [28] developed a methodology to classify fixture design information into two libraries: conceptual design information and fixture unit information. Sun et al. [29] applied CBR algorithm in the modular fixture. Memory organization packages technique is applied to organize locating data, knowledge and case base. Vukelic et al. [30] used a combination of feature-based, knowledgebased and geometry-based methodology for developing a complex system for fixture selection, modification and design. Peng et al. [31] developed a virtual reality-based integrated system using CBR for machining fixture. An approach combining the rule-based reasoning and fuzzy comprehensive judgment method was proposed for reasoning suitable locating features and clamping features. Hashemi et al. [32] proposed a CBR method. To improve the efficiency of the fixture design, indexing and retrieval approaches ware adopted and then improved. In the design method, the appropriate workpiece in the first level of database by using design requirement was found. This allowed the proper conceptual fixture design to be achieved by retrieving a related fixture case from the second level. $\mathrm{Fu}$ et al. [33] demonstrated a rule-based algorithm which defines fixture design for a set of operations. A rule-based algorithm was used to define all feasible manufacturing operations for the given CAD model. A hierarchical search technique was developed to discern which operations were best in terms of manufacturing time, cost, and fixture quality.

Each of the approaches has its own advantages and drawbacks. The artificial neural networks have been successfully used to generate conceptual fixture design solutions. So far, approaches to application of ANN in fixture design allow generation of partial as well as conceptual fixture design solutions. A substantial problem regarding the ANN design pertains to collecting the critical mass of pertinent information for training, which would be based on a systematic processing of case studies. The expert systems have been mostly used for the generation of partial fixture solutions, i.e., for the selection of locating and clamping elements. The other functional groups of fixture components were omitted from consideration. Application of CBR allows us to use previous design solutions in order to generate novel solutions. The problem related to application of CBR methodology comes to the fore when there are no sufficiently similar design solutions in the database, in other words, how to design a fixture completely from scratch.

The objective of this research is to take what is best from the systems for fixture design optimization, and systems for fixture design, in order to develop an integral system for automated fixture design. The integration of these two system segments should allow output from one segment to be used as the input into another. The system should also be capable of correcting output values from various design stages should they prove inadequate. The ultimate objective is to generate complete fixture solutions which completely present details of physical structure elements based on the previously defined tasks for each element. In addition, one of the goals is to develop a sufficient number of production rules for the 
selection of fixture elements which are critical for successful generation of novel fixture designs. Such rules should enable users to select fixture elements from all functional groups - not only the selection of locating and clamping elements, but also fixture body elements, tool guiding elements, tool aligning elements, connecting elements, and add/on elements. In this way, it is possible to automatically generate a complete fixture design.

\section{System structure}

Based on the previous analysis and discussion, a global concept of the system for automated fixture design and optimization was defined. The structure consists of four major modules (Fig. 1): modules for input information, optimization, selection of fixture elements, and output information.

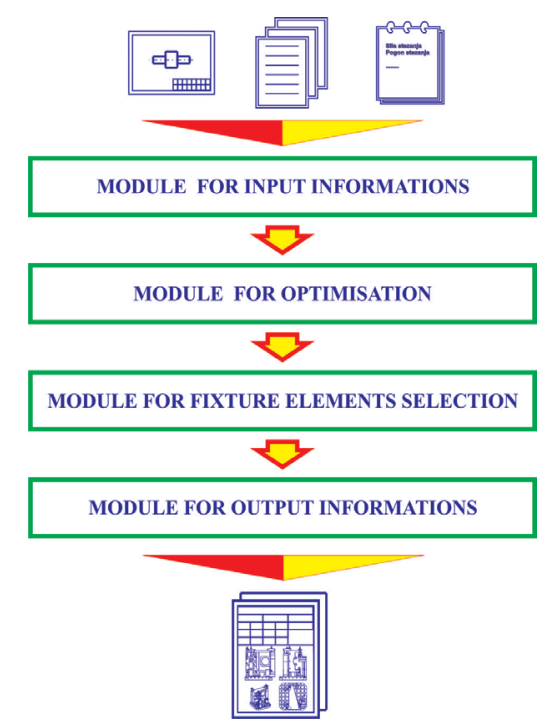

Figure 1 Global system structure

The system input consists of coded information. Coded information can be used to define optimal positions of locating and clamping elements. Fixture element solutions can be stored in the database under particular designation. During synthesis of a novel fixture design, one can divide fixture into various functional units, and approach the design process in stages. Finally, the fixture is assembled and technical documentation is generated as system output.

\subsection{Defining workpiece surfaces}

One of the key problems which have to be solved in automated fixture design is the unambiguous definition of characteristic workpiece surfaces. Orientation of any surface in space can be unambiguously defined by defining its coordinates in a coordinate system, which can be optionally attached to some characteristic point on the workpiece (Fig. 2). In both of these cases it is possible to use a special coding system to completely define particular surfaces on the workpiece. Each surface can have its own coordinate system. Cartesian coordinate system is suitable for elementary workpiece surfaces. The reference coordinate system $\left(0_{X Y Z}\right)$, which is the reference for defining wokrpiece surfaces, can have arbitrary orientation in space. However, for simplicity's sake, it is convenient to fix it to a point on a workpiece. Testing showed that it is most convenient to place its origin on the intersection of the locating surfaces (if possible), so that coordinates belong to locating surfaces. Location of a local coordinate system, $\left(\mathrm{A}_{X Y Z}\right)$, which defines some elementary surface, should be set so that it belongs to elementary surfaces. Relative to the origin of a local coordinate system, it is necessary to unambiguously define the geometry of workpiece elementary surface. For the sake of efficiency, there should be defined as much as possible characteristic surface types. Should some additional surface types be required in the design process, their unambiguous mathematical description should be provided.

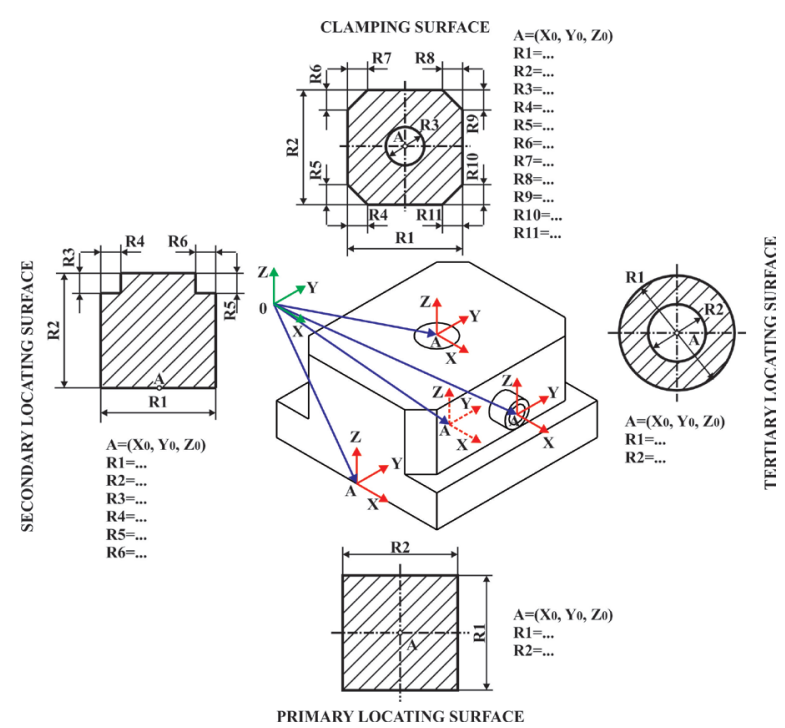

Figure 2 An example of definition of characteristic workpiece surfaces

\subsection{Module for input informations}

Input information can be broken down into two principal groups: information on a workpiece, and manufacturing information.

In general, input information comprises information on:

- type of machining (turning, drilling, milling, grinding, etc.),

- main machine tool group (lathes, drilling machines, milling machines, grinders, etc.),

- machine tool sub-group (universal lathe, copy lathe, revolver lathe, single-spindle pillar drilling machine, horizontal single-spindle boring machine, multispindle drill head machines, aggregate drilling machines, horizontal milling machine, vertical milling machine, universal milling machine, copy milling machine, surface grinding machine, universal grinding machine, copy grinding machine, etc.)

- type of machine tool (conventional, $\mathrm{CNC}$ ),

- number of workpieces being machined at the same time (one, two, three, etc.),

- number of machining surfaces (single surface, more identical surfaces in linear displacement, more identical surfaces in circular displacement, etc.),

- method of connecting fixture with machine tool (spindle, work table), 
- method of arresting fixture during machining (by fixture elements, manually),

- batch size,

- $\quad$ workpiece shape (prismatic, rotational, irregular),

- overall workpiece dimensions (length, height, width, diameter, etc.),

- number of degrees of freedom arrested with locating elements $(3,4,5,6)$

- workpiece locating method (3-2-1, 4-1-1),

- basic fixture characteristic (locating and clamping on external surfaces, locating and clamping on internal surfaces, locating and clamping on internal and external surfaces, etc.),

- $\quad$ workpiece shape (prismatic, cylindrical, etc.)

- forces and moments acting during machining process,

- shape of locating surfaces (external flat, internal flat, external cylindrical, internal cylindrical, external conical, internal conical, external spherical, internal spherical, etc.),

- integrality of locating surfaces (continuous, steplike),

- quality of locating surfaces (ISO tolerance grade),

- type of locating surfaces (ring, triangle, quadrilateral, rhomb, trapeze, etc.),

- characteristic dimensions of locating surfaces,

- position of primary locating surfaces relative to machine tool work table (horizontal, vertical, angled),

- number of clamping force directions,

- shape of clamping surfaces in particular directions,

- clamping scheme in particular directions (clamping force is parallel to the plane of cutting moment, clamping force is orthogonal to the plane of cutting moment, clamping force is at an angle relative to the plane of cutting moment, etc.),

- clamping drive in particular directions (manual, pneumatic, hydraulic, electrical, combined),

- direction of cutting force relative to locating surface in particular directions (parallel, orthogonal, etc.),

- types of clamping surfaces by particular directions,

- characteristic dimensions of clamping surfaces.

Some of this input information is specific to particular machining cuts. So, for example, the required input information for drilling on conventional drilling machines is the drilling diameter, similarly, for milling on conventional milling machines - it is necessary to know the number of dimensions which define the machining surface.

Input information is then entered and coded. The coded information required for the design of a new fixture solution, is later re-used by the various system modules.

\subsection{Module for optimization}

The main function of the module for optimization is to determinate surfaces and points witch will be used for locating and clamping of workpieces. Thus, the fixture structure is defined, since locating and clamping elements are most important component parts of every fixture. These elements directly impress on processing accuracy, productivity and processing cost, selection of other fixture elements etc.

Determination of locating and clamping points means three basic steps:

- determination of locating surfaces (schemes),

- determination of clamping surfaces (schemes),

- determination of locating and clamping points.

During workpiece machining there are deviations from the required geometry. Machining errors are common to every machining process. The basic criterion of machining accuracy requires that the total machining error must be less than the allowed machining tolerance. The errors which occur prior to and during machining process depend on a large number of factors. These errors involve: geometric machining errors, methodical errors, locating errors, clamping errors, tool setup errors, elastic deformation errors, thermal deformation errors, machining allowance errors, wear errors, internal stress errors, and errors of cutting system dynamics.

Locating error has great impact on the total machining error. Locating errors occur either due to adoption of auxiliary seat, or due to a clearance between the locating surfaces on the workpiece, and the corresponding fixture elements (locating elements which are interfacing locating surfaces). In contrast to all other errors which occur prior to or after the machining, locating error is unique in that it can be exactly determined at all times. Therefore, its numerical value and impact on the total machining error are known. Locating surfaces should be always chosen so that they do not impact the total machining error.

Structure of segment for determination of surfaces for locating and clamping is represented in Fig. 3. With regard to the input data, i.e. orientation of workpiece in manufacturing process, workpiece surfaces, workpiece dimensions, and workpiece tolerance generation of possible locating surfaces has been worked out and certain numbers of freedom degrees have to be discarded from a workpiece.

A workpiece can be located in the way that its locating error $(\Delta l)$ is equal to zero or nonzero. From the point of view of manufacturing accuracy, it is better to have the zero value for locating error. However, in certain conditions, it is possible that the locating error is nonzero and that its sum with other manufacturing sum error $(\Delta s)$ is less than manufacturing tolerance $(T)$ i.e. $\Delta l+\Delta s<T$. However, the fixture structure and its manufacturing can be significantly bigger, and by that this solution can be taken as better regarding to the previous one when there is no locating error. Because of that, it is necessary to check the value of the locating error after defining possible solutions for locating schemes. All solutions that satisfy prerequisite of the nonzero or small locating error can be selected. Decision for actual scheme is made in the next modules. One or more solutions for locating schemes are output from this segment.

From selected locating schemes, possible clamping schemes are being done, and they are on surfaces placed against the locating surfaces. 


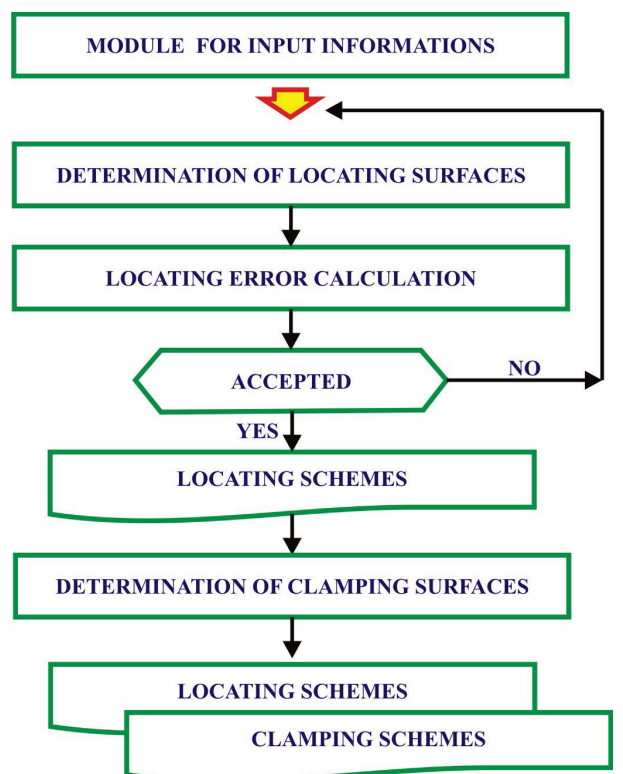

Figure 3 Definition of locating and clamping surfaces

After defining possible locating and clamping scheme, points (positions) for locating and clamping are also defined, i.e., places of contact between these elements and the workpiece.

Defining of position for locating and clamping elements consists of two steps (Fig. 4):

- defining initial position for locating and clamping elements,

- $\quad$ generating optimal position for locating and clamping elements.

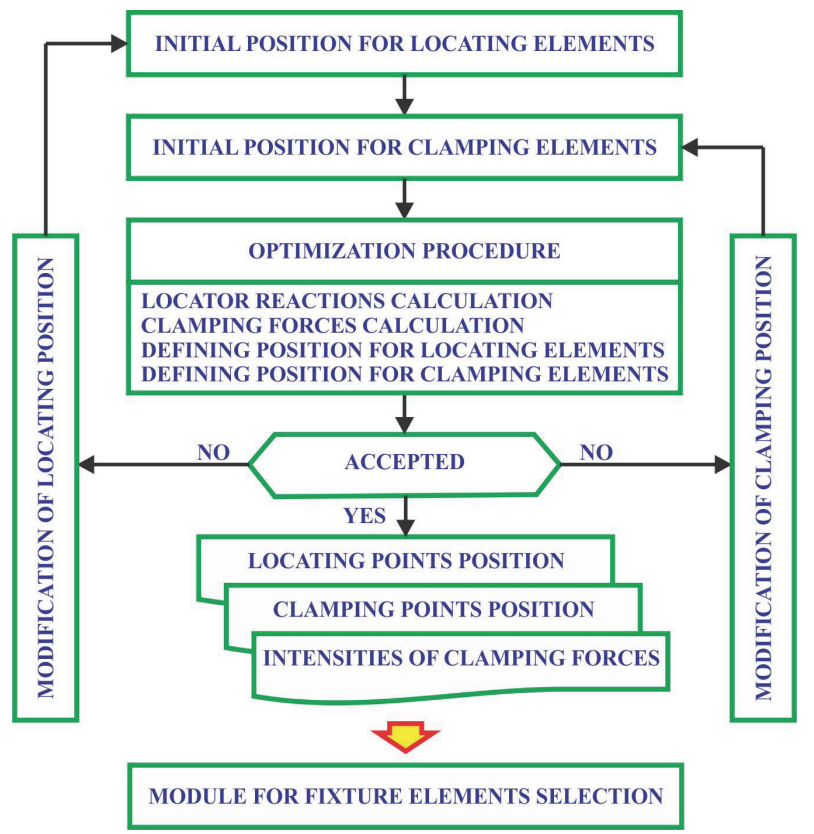

Figure 4 Definition of position for locating and clamping elements

The basic assumption in the newly proposed approach is that a fixture element can be located anywhere on the appropriate surface, and, by extension, it can be moved in any direction on the existing surface. This approach is especially sensitive to proper defining of the locating and clamping surface. Especially important is to observe particular restrictions. Firstly - the proper number of arrested degrees of freedom, with the precisely defined number of locating elements (Fig. 5). Secondly fixture elements must not be placed on surfaces which do not exist, even though they lie in the plane of the locating surface (Fig. 6). Thirdly - fixture elements must not be placed on existing surfaces prior to machining. This means that the element must not be placed on a tool path trajectory during machining (Fig. 7). For these reasons, locating and clamping surfaces should be clearly marked so as to prevent the placement of locating and clamping elements on inappropriate surfaces.

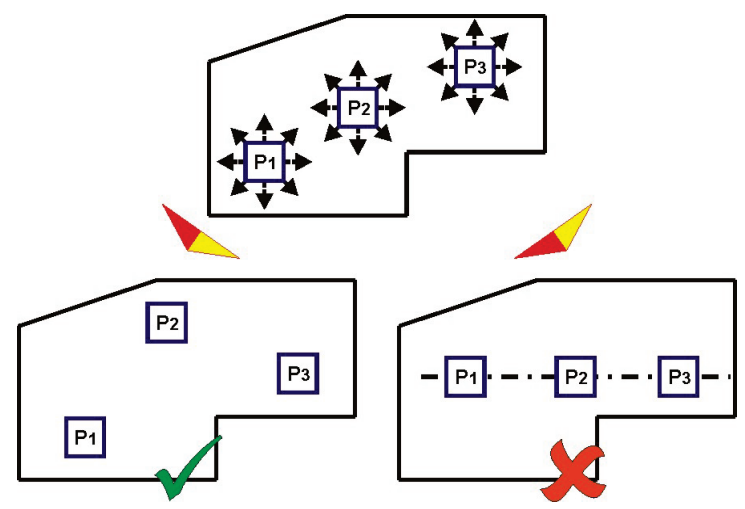

Figure 5 Correct (arresting three degrees of freedom) and incorrect (arresting two degrees of freedom) placement of locating elements
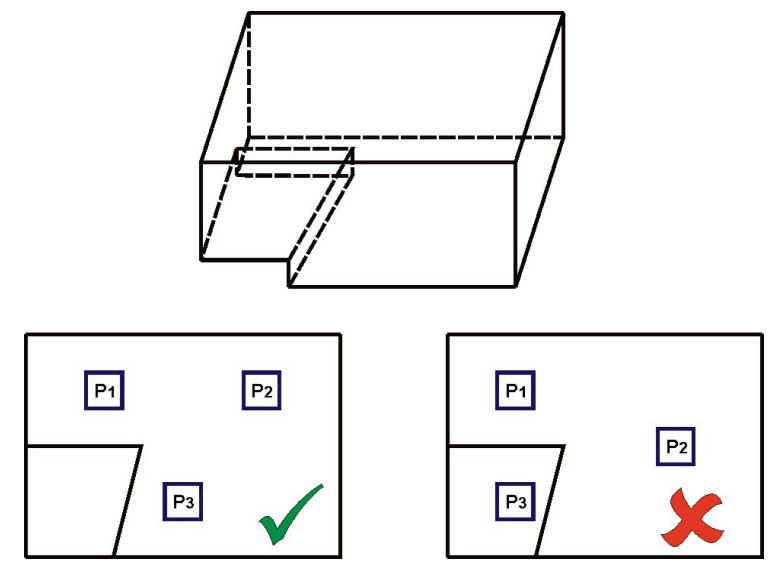

Figure 6 Correct (existent surface) and incorrect (non-existent surface) placement of locating elements

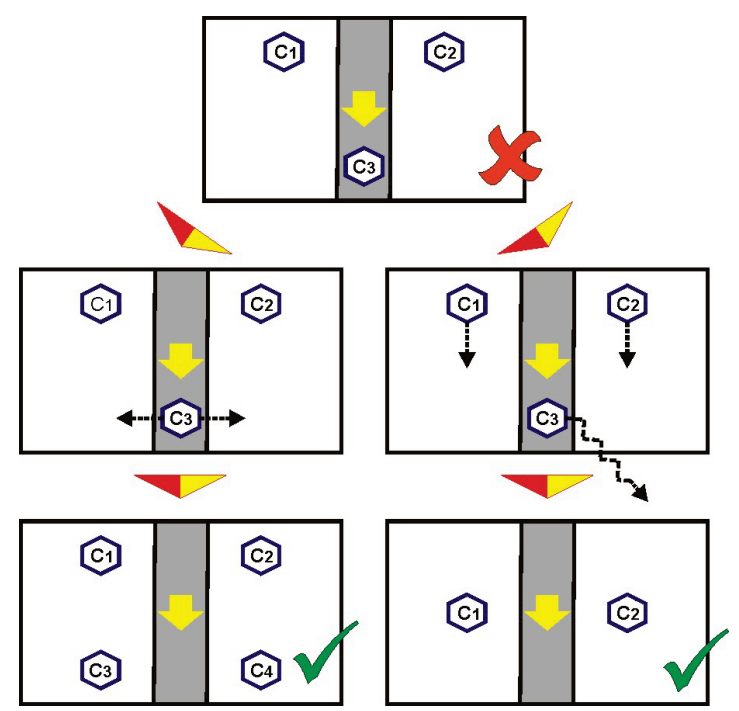

Figure 7 Collision between cutting tool and clamping element and possible ways of correction 
When defining placement positions of locating and clamping fixture elements, the goal function is to minimize the intensity of forces which act on the workpiece during machining. This allows minimization of workpiece deformations while preventing any movement relative to its original position (established by locating and clamping) during machining. Following restrictions should be observed:

- Vectorial sum of forces and moments acting on workpiece during machining should equal zero.

- Locator reactions (locating elements forces) must remain positive during the entire machining process, i.e., they have to be directed towards workpiece. Negative or zero support reactions indicate loss of contact between workpiece and locating elements.

- All forces must act at a point which belongs to workpiece.

Optimization of the placement of locating and clamping elements is performed by genetic algorithm in this system. In order to find optimum position for locating and clamping elements, characteristic workpiece surfaces are discretized into a number of smaller facets which form a mash of possible positions of locating and clamping elements. During GA initialisation, the initial population is generated. In this particular case, the unknowns are positions and intensities of clamping and locating forces (locator reactions). These forces should be minimal if the workpiece is to suffer minimum deformation. Solution space contains various force combinations. GA is used to search this space in order to find the optimal layout of forces and their intensities. Each feasible solution is represented as a 'chromosome', i.e., sequence of components, where each individual component is termed 'gene'. The module for optimization selects chromosomes to be reproduced based on their measures of deviation. Novel conceptual fixture designs, with lesser deviations (force intensities) than the previous solutions, are generated through genetic operations, such as 'crossing' and 'mutation'. This cycle of operations is repeated through several 'generations', until the combination of force layout and intensities (clamping forces and locator reactions) with minimal values (favourable measure of deviation) is satisfied, i.e., until the stopping criterion is met. This module outputs optimal positions of locating and clamping elements.

\subsection{Module for fixture elements selection}

Structure of the module for selection of fixture elements is shown in Fig. 8. Within this system module, all required fixture elements which belong to various functional groups are selected. In order to allow efficient system operation, the following functional groups of fixture elements were identified: locating, clamping, fixture body, tool guiding, tool aligning, connecting, and add-on elements.

This module functions on symbolic representation and processing of built-in knowledge on the selection of particular fixture elements. The knowledge is represented using formal symbols and data structures coded in a programming language, while the problems are solved using inductive and deductive solutions, through manipulation of the symbols and data structures.

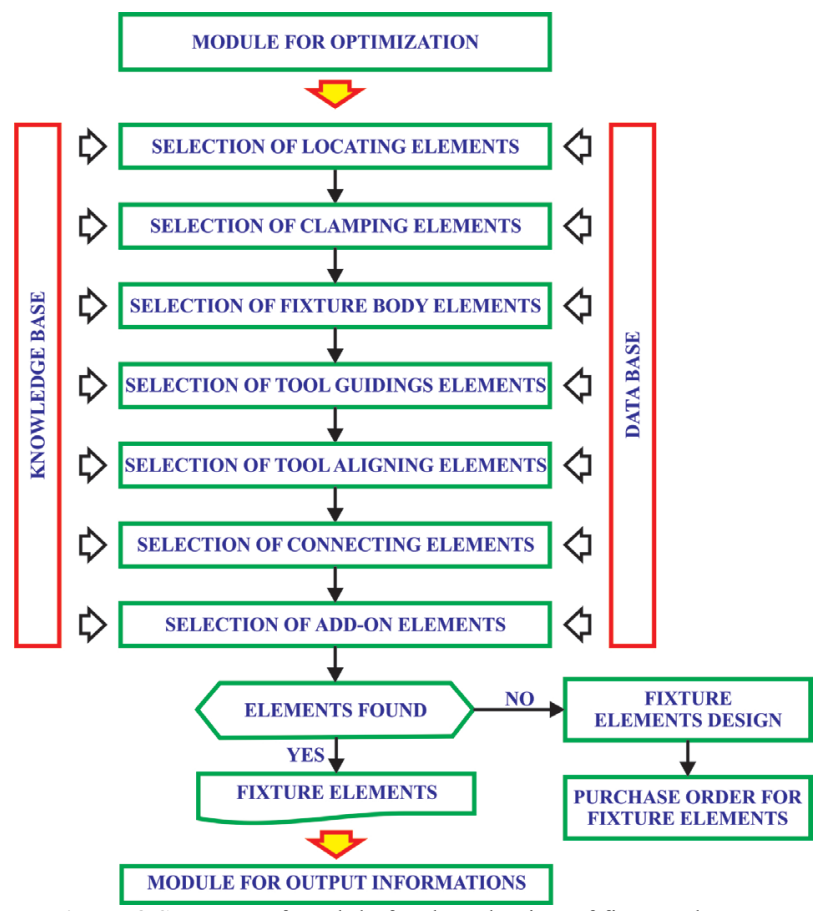

Figure 8 Structure of module for the selection of fixture elements

The basic idea behind production systems is to iteratively apply the rules from the knowledge base to solve the problem which is described by data in the operating memory. An inference engine is used to find the required knowledge in the knowledge base. It operates as a mediator between the knowledge base, and user interface. Inference engine contains a rule interpreter, which is used to process and interpret production rules during system operation. During the inference process, based on initial information stored in the operating memory, and the knowledge which is stored in the knowledge base, the inference engine attempts to find adequate fixture elements. Executing the process it then generates new data in the operating memory, which extends the existing set of data in the operating memory. This updated state of the operating memory can be sufficient for the selection of fixture elements, in which case the process ends there. If that is not the case, then the extended set of data is processed again using the knowledge base, which again updates the data set in the operating memory. The process is re-iterated until a state is reached when there is sufficient data to find the required fixture elements. Otherwise, the system concludes that the solution is impossible to obtain. If required fixture element does not exist, then it is necessary to design that element or purchase it. Such element would also be stored in the data base, and the appropriate production rules for its selection would have to be generated. After a new production rule is entered into the knowledge base or an existing one is modified, the fixture on which that rule was applied in the design process can be automatically detected in the future. In that case, a fixture designer has to decide whether the new rule can be used solely on the existing (previously designed) fixture layout, or several of them, and to undertake appropriate corrections. Alternatively, he/she decides not 
to apply the new rule, but instead to keep both the existing rule and the new one in the database. In that case, in the ensuing design stages, the system shall generate at least two elements which can perform the same required function.

\subsection{Module for output information}

The structure of the output information module is shown in Fig. 9. The inputs into the last segment of the system are the previously generated data on fixture elements and the information on positions of particular fixture elements relative to a workpiece. In the first step, fixture is assembled using the database, i.e., the file with all the fixture elements. The required elements are entered into the assembly one-by-one, for better clarity and to avoid collisions. A workpiece is entered first, then the locating elements, clamping elements, followed by the remaining fixture elements. Once the fixture is assembled, the design solution is analysed. This analysis comprises detection and removal of possible collisions.

There are three types of collisions which can be identified:

- The collision between immovable fixture elements can prevent successful fixture assembly. The same holds for the collision between adjustable and exchangeable fixture elements, which is often the case in group technology.

- The collision between fixture elements and workpiece can directly influence machining process requirements, hindering the set-up and take-out of workpiece from the fixture. Also, workpiece can often be setup into fixture in more than one variant. This can cause various errors in locations of the machined features.

- The collision between fixture elements and the cutting tool can occur in cases when placing fixture elements along the tool path during the machining. This can damage the tool or fixture elements and in some cases can result in tool and fixture elements failure, damaging the machine and other parts of machining system or even injuring workers.

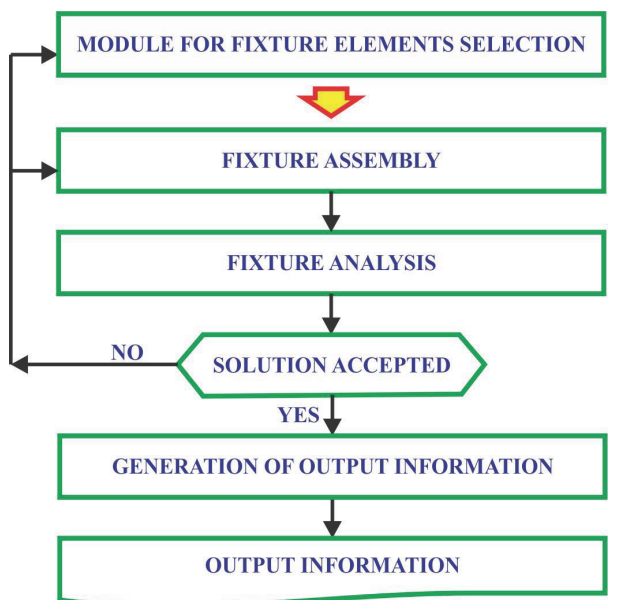

Figure 9 Structure of output information module

If it is not possible to obtain a satisfactory fixture solution, the modules for fixture synthesis, and selection or design of additional fixture elements must be used again. After the final fixture solution is formed, the required output information is generated - fixture drawings, and a bill of materials. Should any additional information be required, it can be generated within this system module.

\section{System functioning}

Within the input information module, all information required for fixture solution design and optimization is coded. Input information coding (Fig. 10) is performed by entering data into a form.

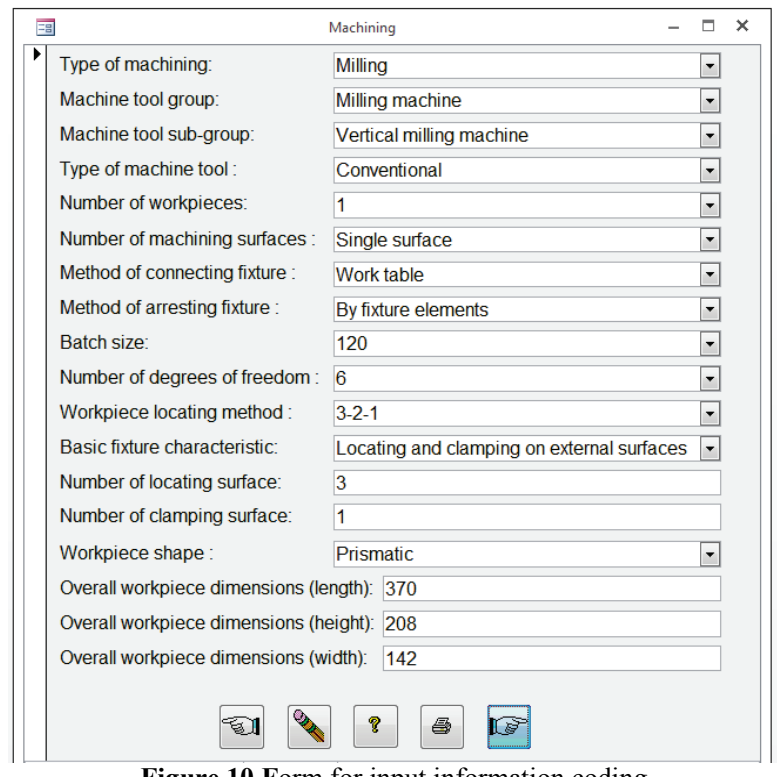

Figure 10 Form for input information coding

Defined within the optimization module are optimal positions of elements for location and clamping. The first step to perform is definition of candidate locating surfaces. Depending on the selected locating scheme and the type of required machining, allowed locating error is automatically calculated. Shown in Fig. 11 are the characteristic forms which allow definition of possible locating schemes in the case of workpiece locating over a flat surface.

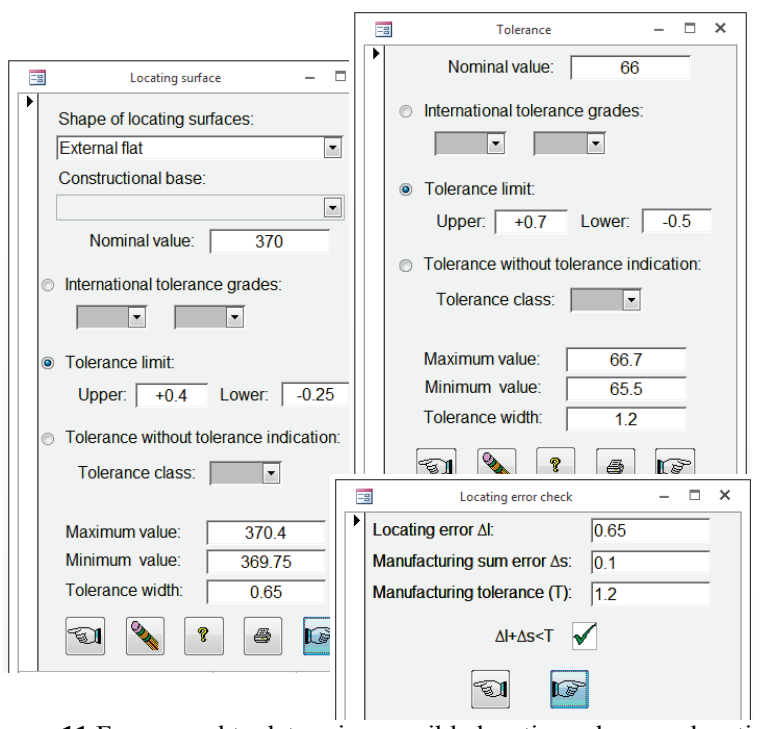

Figure 11 Forms used to determine possible locating schemes - locating error check 
Based on the calculated locating error, workpiece location surfaces are selected together with the clamping surfaces. Local coordinate systems are also defined to accommodate each geometrical form and initial position coordinates for locating and clamping elements are pinpointed (Fig. 12).

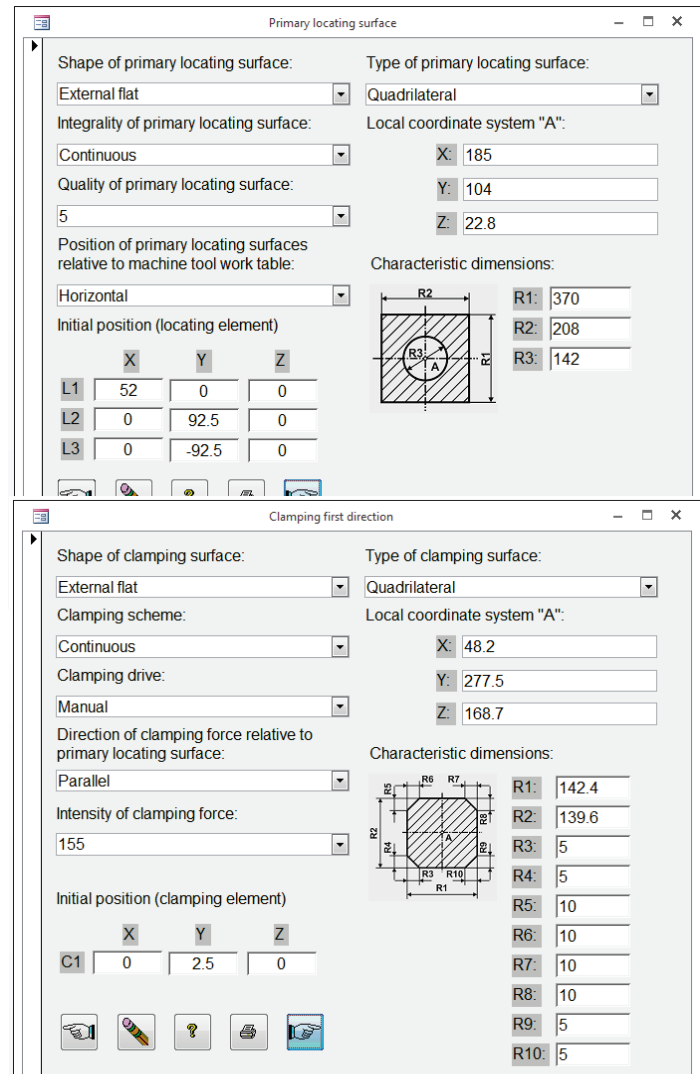

Figure 12 A segment of the forms for defining locating/clamping surfaces and initial locating/clamping points

The next stage consists of fixture solution design optimization. The optimization procedure is done by a genetic algorithm based on previously entered information on the characteristic workpiece surfaces and magnitudes of forces acting on a workpiece during machining. The following stopping criteria can be used: number of iterations (generations), number of iterations without improvement, time limit, maximum value of clamping force or minimum value of support reactions. When, after a number of completed iterations, the stopping criterion is met, the optimization process is stopped and the best members of the current population are adopted as solution (Fig. 13).

Selection of fixture elements from the fixture elements database runs according to production rules stored in the knowledge base. The inference mechanism selects specific knowledge based on which particular fixture elements are chosen. The list of elements (Fig. 14) is formed based on input information generated from the input data module, production rules for the selection of each element from each functional group and the information derived from the module for fixture design optimization (locating and clamping schemes). Shown in Fig. 14 is the form with fixture elements classified into functional groups, based on which fixture assembly was performed.

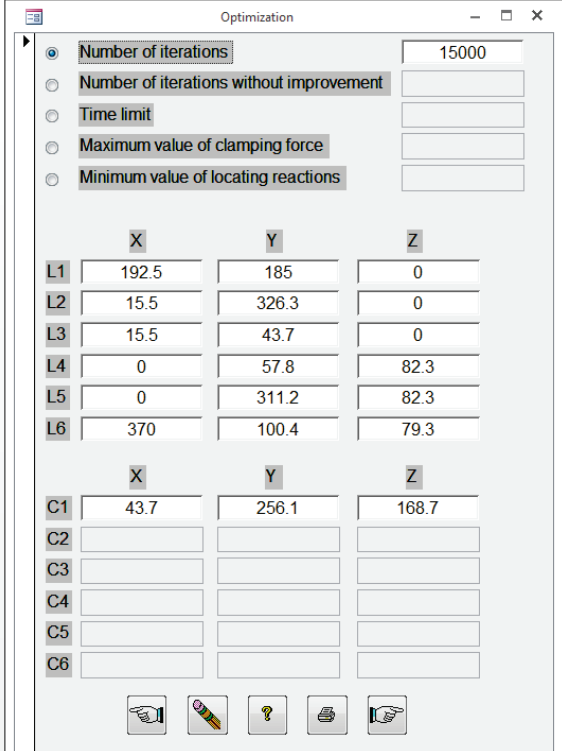

Figure 13 Optimization of positions for locating and clamping elements

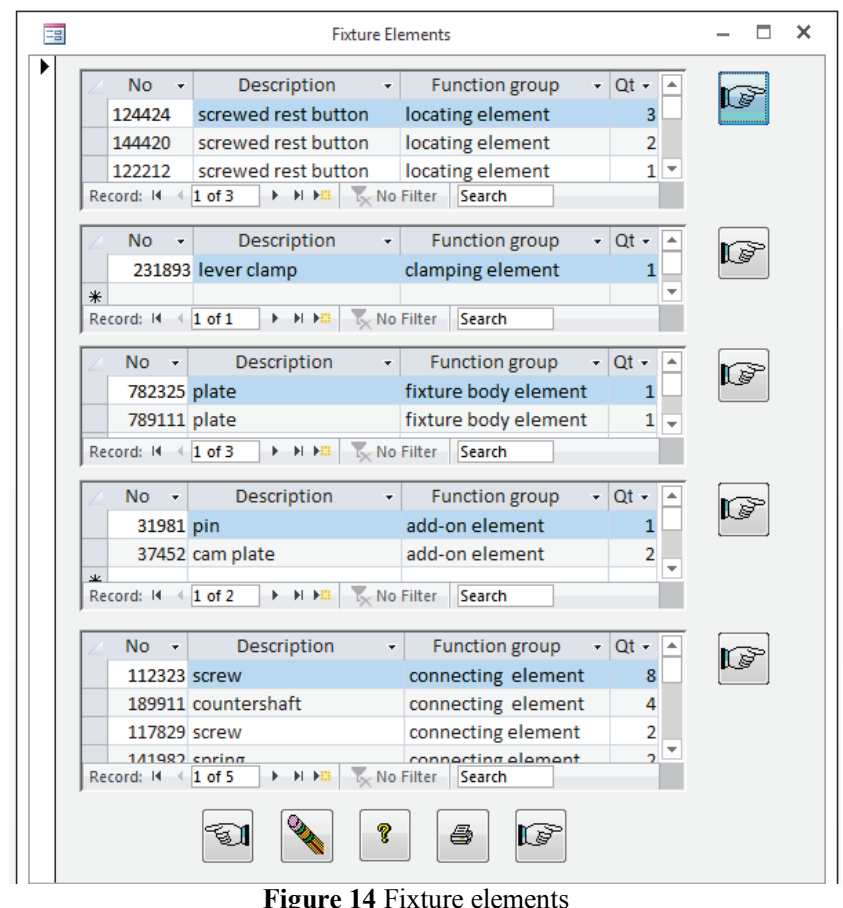

In the insuing step, the module for output information is activated in order to perform fixture assembly. During assembly of a novel fixture solution, particular fixture elements are selected from the form which was previously generated for fixture assembly (Fig. 14). In order to avoid collision, fixture elements are entered gradually into assembly - one by one. The workpiece is entered first, followed by the locating and clamping elements, while elements from the remaining functional groups come in the end. The elements for locating and clamping are entered to positions previously defined by the optimization module. Every fixture element should, within constraints, be placed on a specified position. Once the fixture was assembled, the design solution was analysed in terms of possible collisions and their prevention. Output results are shown in Figure 15. 

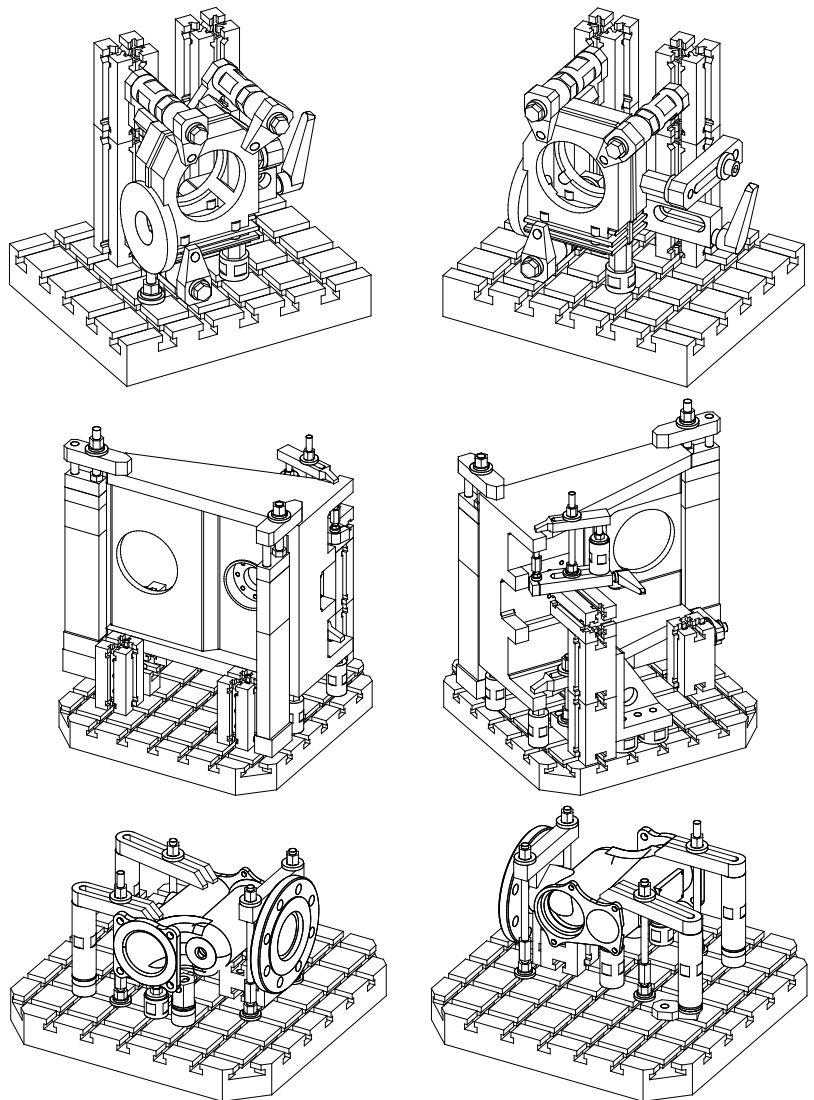

Figure 15 Output results from the system

\section{Conclusion}

The investigation, presented in this paper, allowed formulation of basic prerequisites for the development of knowledge base which encompasses more functional groups of fixture elements, and reliable rules for the selection of fixture elements. Beside the selection of elements for locating and clamping, also featured by the existing CAFD systems, the proposed system additionally allows selection of: fixture body elements, tool guiding elements, tool aligning elements, connecting elements, and a substantial number of add-on elements. In order to widely use the developed system for automated fixture design, it is necessary to complete the building of its knowledge base. Special attention should be focused on the development of additional production rule for the selection of securing elements (add-on elements), and elements for bridging height and length distances (add-on elements). The kinetic model of fixture considers workpiece as a rigid, not elastic, body. In other words, the kinetic model does not allow for workpiece deformations. Instead of examining all possible requirements, this investigation is focused on defining a general framework. Once the framework is established, it will be possible to identify, study, and integrate all other requirements into the proposed system.

\section{References}

[1] Tadic, B.; Bogdanovic, B.; Jeremic, B.M.; Todorovic, P.M.; Luzanin, O.; Budak, I.; Vukelic, D. Locating and clamping of complex geometry workpieces with skewed holes in multiple-constraint conditions. // Assembly Automation, 33, 4(2013), pp. 386-400. DOI: 10.1108/AA-09-2012-074
[2] Bi, Z. M.; Zhang, W. J. Flexible fixture design and automation: Review, issues and future directions. // International Journal of Production Research. 39, 13(2001), pp. 2867-2894. DOI: 10.1080/00207540110054579

[3] Vukelic, D.; Ostojic, G.; Stankovski, S.; Lazarevic, M.; Tadic, B.; Hodolic, J.; Simeunovic, N. Machining fixture assembly/disassembly in RFID environment. // Assembly Automation. $\quad 31, \quad 1(2011)$, pp. 62-68. DOI: 10.1108/01445151111104182

[4] Todorovic, P.; Buchmeister, B.; Djapan, M.; Vukelic, D.; Milosevic, M., Tadic, B.; Radenkovic, M.: Comparative Model Analysis of Two Types of Clamping Elements in Dynamic Conditions. // Tehnicki vjesnik-Technical Gazette. 21 (6)2014, pp. 1273-1279.

[5] Pehlivan, S.; Summers, J. D. A review of computer-aided fixture design with respect to information support requirements. // International Journal of Production Research. 46, 4(2008), pp. 929-947. DOI: 10.1080/00207540600865386

[6] Leopold, J.; Hong, L. Clamping modelling: state-of-the-art and future trends. // Industrial Robot: An International Journal. $\quad 36, \quad 3(2009)$, pp. 249-254. DOl: 10.1108/01439910910950513

[7] Boyle, I.; Rong, R.; Brown, D. C. A review and analysis of current computer-aided fixture design approaches. // Robotics and Computer-Integrated Manufacturing. 27, 1(2011), pp. 1-12. DOI: 10.1016/j.rcim.2010.05.008

[8] Krishnakumar, K; Melkote, S. N. Machining fixture layout optimization using the genetic algorithm. // International Journal of Machine Tools and Manufacture. 40, 4(2000), pp. 579-598. DOI: 10.1016/S0890-6955(99)00072-3

[9] Hamedi, M. Intelligent fixture design through a hybrid system of artificial neural network and genetic algorithm. // Artificial Intelligence Review. 23, 3(2005), pp. 295-311. DOI: 10.1007/s10462-004-7187-z

[10] Sanchez, H.T.; Estrems, M.; Faura, F. Fixturing analysis methods for calculating the contact load distribution and the valid clamping regions in machining processes. // International Journal of Advanced Manufacturing Technology. 29, 5(2006), pp. 426-435. DOI: 10.1007/s00170005-2531-2

[11] Prabhaharan, G.; Padmanaban, K.P.; Krishnakumar, R. Machining fixture layout optimization using FEM and evolutionary techniques. // International Journal of Advanced Manufacturing Technology. 32, 11-12(2007), pp. 1090-1103. DOI: 10.1007/s00170-006-0441-6

[12] Asante, J.N. A combined contact elasticity and finite element-based model for contact load and pressure distribution calculation in a frictional workpiece-fixture system. // International Journal of Advanced Manufacturing Technology. 39, 5-6(2008), pp. 78-88. DOI: 10.1007/s00170007-1187-5

[13] Chen, W.; Ni, L.; Xue, J. Deformation control through fixture layout design and clamping force optimization. // International Journal of Advanced Manufacturing Technology. 38, 9-10(2008), pp. 860-867. DOI: 10.1007/s00170-007-1153-2

[14] Vishnupriyan, S.; Majumder, M. C.; Ramachandran, K. P. Optimal fixture parameters considering locator errors. // International Journal of Production Research. 49, 21(2011), pp. 6343-6361. DOI: 10.1080/00207543.2010.532167

[15] Tadic, B.; Jeremic, B.; Todorovic, P.; Vukelic, D.; Proso, U.; Mandic, V.; Budak, I. Efficient workpiece clamping by indenting cone shaped elements. // International Journal of Precision Engineering and Manufacturing, 13, 10(2012), pp. 1725-1735. DOI: 10.1007/s12541-012-0227-8

[16] Vishnupriyan, S. Effect of system compliance and workpiece dynamics on machining error. // Assembly Automation. $\quad 32, \quad 2(2012)$, pp. 175-184. DOI: $10.1108 / 01445151211212325$ 
[17] Liu, Z.; Wang, M. Y.; Wang, K.; Mei, X.: Multi-objective optimization design of a fixture layout considering locator displacement and force-deformation. // International Journal of Advanced Manufacturing Technology. 67, 58(2013), pp. 1267-1279. DOI 10.1007/s00170-012-4564-7

[18] Bai, X.; Hu, F.; He, G.; Ding, B. A Memetic Algorithm for multi-objective fixture layout optimization. // Proceedings of the Institution of Mechanical Engineers - Part C: Journal of Mechanical Engineering Science, 229, 16(2015), pp. 3047-3058. DOI: 10.1177/0954406214565802

[19] Wang, H.; Huang, L.; Yao, C.; Kou, M.; Wang, W.; Huang, B.; Zheng, W: Integrated Analysis Method of Thin-Walled Turbine Blade Precise Machining. // International Journal of Precision Engineering and Manufacturing. 16, 5(2015), pp. 1011-1019. DOI: 10.1007/s12541-015-0131-0

[20] Tadic, B.; Vukelic, D.; Miljanic, D.; Bogdanovic, B.; Macuzic, I.; Budak, I.; Todorovic, P. Model testing of fixture-workpiece interface compliance in dynamic conditions. // Journal of Manufacturing Systems, 33, 1(2014), pp. 76-83. DOI: 10.1016/j.jmsy.2013.05.004

[21] Dai, J. R.; Nee, A. Y. C.; Fuh, J. Y. H.; Kumar, S. A. An approach to automating modular fixture design and assembly. // Proceedings of the Institution of Mechanical Engineers - Part B: Journal of Engineering Manufacture. 211, 7(1997), pp. 509-521. DOI: 10.1243/0954405971516464

[22] Lin, Z. C.; Huang, J. C. The application of neural networks in fixture planning by pattern classification. // Journal of Intelligent Manufacturing. 8, 4(1997), pp. 307-322. DOI: 10.1023/A:1018541812444

[23] Ma, W.; Li, J.; Rong, Y. Development of automated fixture planning systems. // International Journal of Advanced Manufacturing Technology. 15, 3(1999), pp. 171-181. DOI: 10.1007/s001700050054

[24] Kumar, S. A.; Subramaniam, V.; Teck, T. B. Conceptual design of fixtures using machine learning techniques. // International Journal of Advanced Manufacturing Technology. 16, 3(2000), pp. 176-181. DOI: 10.1007/s001700050024

[25] Gologlu, C. Machine capability and fixturing constraintsimposed automatic machining set-ups generation. // Journal of Materials Processing Technology. 148, 1(2004), pp. 8392. DOI: 10.1016/j.jmatprotec.2004.01.043

[26] Liqing, F.; Kumar, A. S.: XML-based Representation in a CBR System for Fixture Design. // Computer-Aided Design \& Applications. 2, 1-4(2005), pp. 339-348. DOl: 10.1080/16864360.2005.10738382

[27] Hu, C. Q.; Lin, Z. Q.; Lai, X. M. Concept design of checking fixture for auto-body parts based on neural networks. // International Journal of Advanced Manufacturing Technology. 30, 5-6(2006), pp. 574-577. DOI: 10.1007/s00170-005-0039-4

[28] Boyle, I.; Rong, K., Brown, D. C. CAFixD: a case-based reasoning fixture design method. Framework and indexing mechanisms. // Journal of Computing and Information Science in Engineering. 6, 1(2006), pp. 40-48. DOl: 10.1115/1.2161229

[29] Sun, H. S.; Chen, L. J. Knowledge representation and reasoning methodology based on CBR algorithm for modular fixture design. // Journal of the Chinese Society of Mechanical Engineers, 28, 6(2007), pp. 593-604.

[30] Vukelic, D.; Zuperl, U.; Hodolic, J. Complex system for fixture selection, modification, and design. // International Journal of Advanced Manufacturing Technology. 45, 78(2009), pp. 731-748. DOI: 10.1007/s00170-009-2014-y

[31] Peng, G.; Chen, G.; Liu, X. Using CBR to develop a VRbased integrated system for machining fixture design. // Assembly Automation. 30, 3(2010), pp. 228-239. DOl: 10.1108/01445151011061127
[32] Hashemi, H.; Shaharoun, A. M.; Sudin, I. A case-based reasoning approach for design of machining fixture. // International Journal of Advanced Manufacturing Technology. 74, 1-4(2014), pp. 113-124. DOl: 10.1007/s00170-014-5930-4

[33] Fu, W.; Campbell, M. I. Concurrent fixture design for automated manufacturing process planning. // International Journal of Advanced Manufacturing Technology, 76, 14(2015), pp. 375-389. DOI: 10.1007/s00170-014-6247-z

\section{Authors' addresses \\ dr. sc. Djordje Vukelic \\ University of Novi Sad \\ Faculty of Technical Sciences \\ Trg Dositeja Obradovića 6, 21000 Novi Sad, Serbia \\ E-mail: vukelic@uns.ac.rs}

dr. sc. Goran Simunovic

Josip Juraj Strossmayer University of Osijek

Mechanical Engineering Faculty in Slavonski Brod

Trg Ivane Brlić Mažuranić 2, 35000 Slavonski Brod, Croatia

E-mail: gsimun@sfsb.hr

dr. sc. Branko Tadic

University of Kragujevac

Faculty of Engineering

Sestre Janjic 6, 34000 Kragujevac, Serbia

E-mail: btadic@kg.ac.rs

\section{dr. sc. Borut Buchmeister}

University of Maribor

Faculty of Mechanical Engineering

Smetanova 17, 2000 Maribor, Slovenia

E-mail: borut.buchmeister@um.si

dr. sc. Tomislav Saric

Josip Juraj Strossmayer University of Osijek

Mechanical Engineering Faculty in Slavonski Brod

Trg Ivane Brlić Mažuranić 2, 35000 Slavonski Brod, Croatia

E-mail: tsaric@sfsb.hr

dr. sc. Nenad Simeunovic

University of Novi Sad

Faculty of Technical Sciences

Trg Dositeja Obradovića 6, 21000 Novi Sad, Serbia

E-mail: nsimeun@uns.ac.rs 